\title{
Grain Size Depending Dwell-Fatigue Crack Growth in Inconel 718
}

Jonas Saarimäki, Mattias Lundberg and Johan Moverare

The self-archived postprint version of this journal article is available at Linköping University Institutional Repository (DiVA):

http://urn.kb.se/resolve?urn=urn:nbn:se:liu:diva-144395

N.B.: When citing this work, cite the original publication.

Saarimäki, J., Lundberg, M., Moverare, J., (2018), Grain Size Depending Dwell-Fatigue Crack Growth in Inconel 718, Advanced Engineering Materials, 1-7. https://doi.org/10.1002/adem.201700930

Original publication available at:

https://doi.org/10.1002/adem.201700930

Copyright: Wiley (12 months)

http://eu.wiley.com/WileyCDA/ 


\title{
Grain size depending dwell-fatigue crack growth in Inconel 718
}

\author{
Jonas Saarimäki^, Mattias Lundberg and Johan J. Moverare \\ [*] Mr. J. Saarimäki, M. Lundberg, Prof. J. J. Moverare \\ Division of Engineering Materials, Department of Management and Engineering \\ Linköping University, SE-58183 Linköping, Sweden \\ E-mail: jonas.saarimaki@liu.se
}

\begin{abstract}
Inconel 718 is a commonly used superalloy for turbine discs in the gas turbine industry. Turbine discs are normally subjected to dwell-fatigue as a result of long constant load cycles. Dwell-times have been shown to give rise to increased crack propagation rates in superalloys at elevated temperatures. Dwell-time crack propagation behaviour in Inconel 718 has been tested at $550{ }^{\circ} \mathrm{C}$ using $\mathrm{Kb}$ test samples with $2160 \mathrm{~s}$ dwell-times at maximum load and "pure fatigue" tests. The dwell-time effect has been studied for differently processed Inconel 718, i.e., fine grained bar, grain enlarged bar, and cast material. This has been done in order to investigate the effect of grain size on crack propagation. Microstructure characterisation was conducted using scanning electron microscopy techniques such as electron channelling contrast imaging and electron backscatter diffraction. Time dependent crack propagation rates are strongly affected by grain size. Propagation rates increase with decreasing grain size, whereas crack tip blunting increased with increasing grain size.
\end{abstract}

\section{Introduction}

Superalloys are used in harsh working conditions, i.e., the hot-section of gas turbines and aero engines due to their positive combination of mechanical properties and corrosion resistance. These conditions are detrimental to the alloy in the form of, e.g., fatigue, creep, corrosion, and oxidation, which could result in catastrophic failure.

Inconel 718 in its polycrystalline form is a commonly used superalloy. It is a solid solution and precipitation strengthened alloy, with gamma prime $\gamma^{\prime}$ and gamma double prime $\gamma^{\prime \prime}$ precipitates as the strengthening phases. Inconel 718 is recurrently used for high temperature components subjected to cyclic loading, i.e., turbine discs, especially when the risk for fatigue and creep deformation is perceptible. Turbine discs can be subjected to temperatures up to $\sim 550{ }^{\circ} \mathrm{C}$ in land-based gas turbines and up to $\sim 700{ }^{\circ} \mathrm{C}$ in aero engines at which the mechanical properties start to dilapidate. ${ }^{[1]}$

Combining high temperatures up to $700{ }^{\circ} \mathrm{C}$ and sustained periods of high tensile loads can lead to accelerated crack propagation rates, but dwell-times are not the only reason for accelerated crack propagation, environmental aspects also play a significant role and an oxidising environment is recognized as the main reason for accelerated crack propagation rates. ${ }^{[2]-[4]}$ When crack propagation rates increase, a change in crack propagation mechanism can be seen as a transition from transgranular to interganular crack propagation. This has been shown for fine grained and high strength alloys. ${ }^{[2]-[5]}$ Creep deformation effects in lower strength alloys should be considered prudently, due to the stress relaxation that occur ahead of the crack tip. As a result the mechanical crack driving forces are lowered and crack tip blunting will occur if the amount of creep deformation is large enough, which can result in a reduced crack propagation rate. ${ }^{[6]-[8]}$ Overloads applied prior to the dwell-time have also been shown to reduce the dwell-time effect. ${ }^{[9][10]}$

Microstructural and chemical features can also affect crack propagation behaviour of Inconel 718, such as; grain size ${ }^{[5][11]}$, serrated grain boundaries ${ }^{[11]}$, special coincident site 
lattice (CSL) grain boundary orientation ${ }^{[12]}$, Niobium content ${ }^{[13]}$, and the presence of different secondary phases such as Laves phase ${ }^{[14]}$, $\operatorname{carbides}^{[5]}$, and $\delta$-phase ${ }^{[15]}$. Transformation induced compressive or tensile residual stresses caused by the oxidation of constituent phases in Nibased can influence time dependent crack propagation rates. ${ }^{[16]}$ Crack tip oxidation of metal carbides and $\delta$-phase in Inconel 718 are believed to give rise to tensile transformation stresses, crack tip anti-shielding, and increased susceptibility to time dependent crack propagation. ${ }^{[16]}$

The influence of the $\delta$-phase on crack propagation has been pointed out in the work by Ponnelle et al. ${ }^{[15]}$ and Saarimäki et al. ${ }^{[17]}$, where forged and rolled Inconel 718 disc material were investigated. Compact tension (CT) and $\mathrm{Kb}$ test samples were manufactured and subjected to various fatigue cycles at elevated temperatures. It was shown that carbides and $\delta$ phase particles are not randomly distributed in this type of processed materials and that the cellular orientation of $\delta$-phase particles can be linked to the existence of a few hundred microns thick bands, which were referred to as a forming induced arrangement. It was found that the crack preferred to grow in the interface between the $\gamma$-matrix and $\delta$-phase and that the crack propagation rates were lowest for crack fronts perpendicular to the $\delta$-phase alignments. Contradictory to the study by Ponnelle et al. ${ }^{[15]}$, Pédron et $a .^{[5]}$ found that the precipitation of $\delta$-phase along the grain boundaries did not drastically affect the crack propagation rate behaviour. $\gamma / \delta$-interface delamination has also been suggested to be the responsible mechanism behind the dwell-time effect. ${ }^{[15]}$ The effect of delamination was explained to be influenced by the local stress state. The influence of stress state is sometimes also visible in the shape of the crack front. In samples with a semi-circular surface or a corner crack, the phenomenon "crack tunneling" is sometimes observed. Differing constraints between the surface and bulk can cause "crack tunneling"[18] and is generally more pronounced under conditions resulting in intergranular cracking ${ }^{[19]-[22]}$, i.e., dwell-times.

The effects of grain size and precipitate size on fatigue crack propagation behaviour at $427^{\circ} \mathrm{C}$ using a triangular waveform, frequency of $0.33 \mathrm{~Hz}$, and a stress ratio of 0.05 and 0.75 was studied. ${ }^{[23]}$ Their choice of temperature and frequency combination used is within the range of turbine disc conditions. However, it is below the temperature range where creep and/or environmentally assisted damage mechanisms dominate.

The present study is motivated by the fact that no study exists that systematically investigates how grain size between differently processed Inconel 718 affects crack propagation behaviour during dwell-fatigue. A test program was carried out to characterise dwell-fatigue crack propagation resistance in bar, grain enlarged bar, and cast Inconel 718 at $550{ }^{\circ} \mathrm{C}$ using $\mathrm{Kb}$ test samples. Detailed metallographic investigations of the tested samples were performed in order to investigate the crack propagation mechanisms.

\section{Experimental procedure}

Inconel 718 in the form of; cast, grain enlarged bar, and fine-grained bar material with the nominal chemical composition listed in Table $\mathbf{1}$ were used for manufacturing $\mathrm{Kb}$ test samples. The cast material was heat treated according to AMS 5383; homogenization at $1080{ }^{\circ} \mathrm{C}$ for $1 \mathrm{~h}$, then water cooled, followed by solution treatment at $980{ }^{\circ} \mathrm{C}$ for $1 \mathrm{~h}$, then water cooled, followed by ageing for $8 \mathrm{~h}$ at $718{ }^{\circ} \mathrm{C}$ and $8 \mathrm{~h}$ at $621^{\circ} \mathrm{C}$ followed by final air cooling. To achieve fine grains during forging the temperature is typically held below the $\delta$ solvus temperature, $\sim 1030{ }^{\circ} \mathrm{C}$, since the $\delta$ phase present in the grain boundaries will hinder grain growth. Later, the fine-grained bar was standard heat treated according to AMS 5663; solution annealing for $1 \mathrm{~h}$ at $945^{\circ} \mathrm{C}$, followed by ageing for $8 \mathrm{~h}$ at $718^{\circ} \mathrm{C}$ and $8 \mathrm{~h}$ at $621^{\circ} \mathrm{C}$ followed by final air cooling. In order to obtain the grain enlarged bar, the fine-grained bar was heat treated accordingly: solution heat treated at $1050{ }^{\circ} \mathrm{C}, 2 \mathrm{~h}$ followed by ageing at $718{ }^{\circ} \mathrm{C}$ and $621{ }^{\circ} \mathrm{C}$ for $8 \mathrm{~h}$ respectively. The solution heat treatment, $1050{ }^{\circ} \mathrm{C}$, is above the $\delta$ solvus temperature, which is why very little or no $\delta$-phase can be seen in the grain enlarged bar. Without the presence of $\delta$-phase grain growth occurs easily at this temperature. Thus, the 
difference in grain size is closely related to the difference in $\delta$-phase morphology. The approximate grain sizes for the three investigated materials were $>700 \mu \mathrm{m}, 200 \mu \mathrm{m}, 20 \mu \mathrm{m}$ for the cast, grain enlarged bar, and fine-grained bar respectively. Specific specimen dimensions and geometries for the Kb samples are found in the work by Storgärds et al. ${ }^{[24]}$ All samples had electro-discharge machined starter notches measuring: width $0.15 \mathrm{~mm}$, length $0.3 \mathrm{~mm}$, depth $0.075 \mathrm{~mm}$ for the fine- and grain enlarged bar material and depth $0.5 \mathrm{~mm}$ for the cast material. Pre-cracks were propagated according to ASTM E647-08 at room temperature using a load ratio of $R=0.05$, and a cyclic frequency of $10 \mathrm{~Hz}$ which resulted in a semi-circular crack $\sim 0.2 \mathrm{~mm}$ ahead of the starter notch before the high temperature testing was started. Precrack measurements were done using potential drop (PD). All subsequent tests were run at $550{ }^{\circ} \mathrm{C}$ and a maximum load of $650 \mathrm{MPa}$ for the three forms: cast, grain enlarged bar, and fine-grained bar materials. "Pure fatigue" tests were run using a sinusoidal waveform at 0.5 $\mathrm{Hz}$ and a load ratio of $R=0.05$. $2160 \mathrm{~s}$ dwell-fatigue tests were run in accordance to ASTM E647-08 with the dwell-time at maximum load and a load ratio of $R=0.05$. In addition, pure "creep" tests with a sustained load and no load cycling were performed on the fine grained and grain enlarged bar.

Table 1. Nominal composition of elements for Inconel 718 in wt. \%.

\begin{tabular}{lllllllllllll} 
Alloy & $\mathrm{Ni}$ & $\mathrm{Cr}$ & $\mathrm{Fe}$ & $\mathrm{Mo}$ & $\mathrm{Nb}$ & $\mathrm{Co}$ & $\mathrm{C}$ & $\mathrm{Mn}$ & $\mathrm{Si}$ & $\mathrm{Cu}$ & $\mathrm{Al}$ & $\mathrm{Ti}$ \\
\hline Inconel 718 & 54.4 & 71.9 & 16.8 & 3.0 & 5.5 & 0.2 & 0.02 & 0.09 & 0.08 & 0.047 & 0.5 & 1.0
\end{tabular}

Crack propagation at $550{ }^{\circ} \mathrm{C}$ for the $\mathrm{Kb}$ test samples was measured according to ASTM E 647-08 using a four probe 12 A channel pulsed direct current potential drop (DCPD) system. Crack length was calculated by dividing the PD over the crack by the PD on the opposite side as a reference. This ratio was then converted to crack length assuming a semicircular crack front via an experimentally acquired calibration curve for Inconel 718 which showed the PD ratio as a function of crack length based on the initial and final crack lengths measured on the fracture surface as well as by measured induced beach marks. ${ }^{[9]}$ The analytical solution for the stress intensity factor, K, was obtained using a pre-solved case for a semi-elliptic surface crack according to ASTM E740-03. The test was interrupted when a total crack length of $2.5 \mathrm{~mm}$ was reached, according to the PD value. Testing was done using a 160 kN MTS servo hydraulic tensile/compression testing machine, equipped with a three-zone high temperature furnace. The nominal load during the dwell time was $\sigma_{\text {dwell }}=650 \mathrm{MPa}$. Data was evaluated using an evaluation code for Kb test samples. ${ }^{[25]-[27]}$

A Hitachi SU70 FEG analytical scanning electron microscope (SEM), operating at 1.5-20 kV was used together with various SEM techniques, i.e., electron channeling contrast imaging (ECCI) ${ }^{[28]}$ and electron backscatter diffraction (EBSD), to study the initial microstucture and the damage after testing.

\section{Results}

Crack propagation rate da/d $N$ versus $\Delta K$ and da/dT versus $K_{\max }$ are presented in Fig. 1 (a) and (b) respectively. In (a) the implementation of a $2160 \mathrm{~s}$ dwell-time results in an accelerated crack propagation rate, a factor of ten, for the fine-grained bar and grain enlarged bar. It also shows that with decreasing grain size crack propagation rate increases. Cast material being much coarser than the grain enlarged bar material exhibits no signs of dwell-time effects. Instead the cast material shows similar crack propagation rates during dwell-fatigue as the fine-grained bar and grain enlarged bar material subjected to "pure fatigue". In (b) the three fine-grained bar creep samples originate from the same batch exhibited both similar and the fastest creep crack propagation rates. The grain enlarged bar creep test, shows a slower creep crack propagation rate compared to the fine-grained bar but is very similar to that of the finegrained bar dwell-fatigue test. The grain enlarged dwell-fatigue tested bar exhibits the second 
to slowest time dependent crack propagation rate. The cast dwell-fatigue test exhibited the slowest time dependent crack propagation rate.
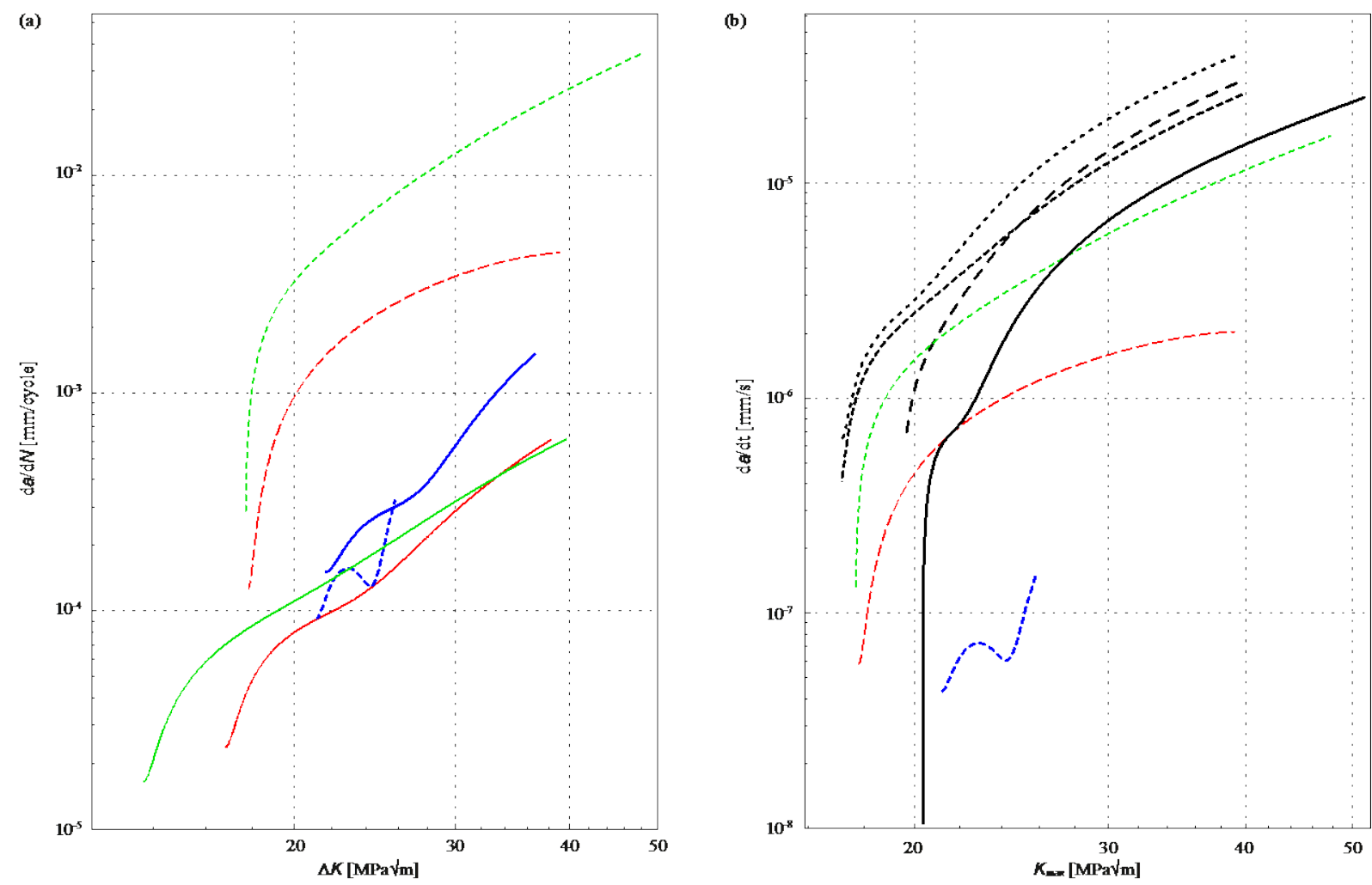

$\begin{array}{lll}\text { Cast "pure fatigue" } & \text { Grain enkarged bar "pure fatigue" — Fine grained bar "pure fatig } \\ \text {-..- Cast } 2160 \mathrm{~s} & \text { - - Grain enkrged bar } 2160 \mathrm{~s} & \ldots-\text { Fine grained bar } 2160 \mathrm{~s}\end{array}$

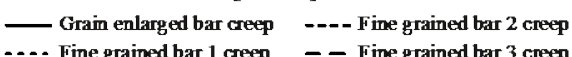

Figure 1. Crack propagation rates run at $550{ }^{\circ} \mathrm{C}$ with $R=0.05$ presented as $\mathrm{da} / \mathrm{d} N$ vs. $\Delta K$ in (a) and $\mathrm{d} a / \mathrm{d} t$ vs. $K_{\max }$ in (b) where the three different fine-grained bar creep samples originates from the same batch.

High resolution SEM revealed that microscopic crack propagation at high temperature took place intergranularly due to oxidation and the creation of nanometric voids for the dwellfatigue and creep tests vis-á-vis transgranularly for the "pure fatigue" tests. Fig. 2 shows the crack path appearance, general microstructure, and crack tip blunting of cross-sectioned samples, all subjected to dwell-fatigue in which: (a)-(c) are images of cast, where (a) shows the general microstructure, (b) crack tip blunting, and (c) the general fracture behaviour exhibiting crystallographic fracture in orthogonal $\{111\}$ planes. (d)-(f) shows the general microstructure of the grain enlarged bar, (e) deformation and branching in the vicinity of the crack tip, and (f) crack tip blunting. (g)-(i) are images of the fine-grained bar material, where (g) shows the general microstructure, (h) deformation and branching in the vicinity of the crack tip, (i) propagation of pores in grain boundaries and intergranular fracture by growth of nano sized pores as well as crack advance along a $\delta$-phase boundary with subsequent severe oxidation of the $\delta$-phase subjected to 2160 s dwell-times. 


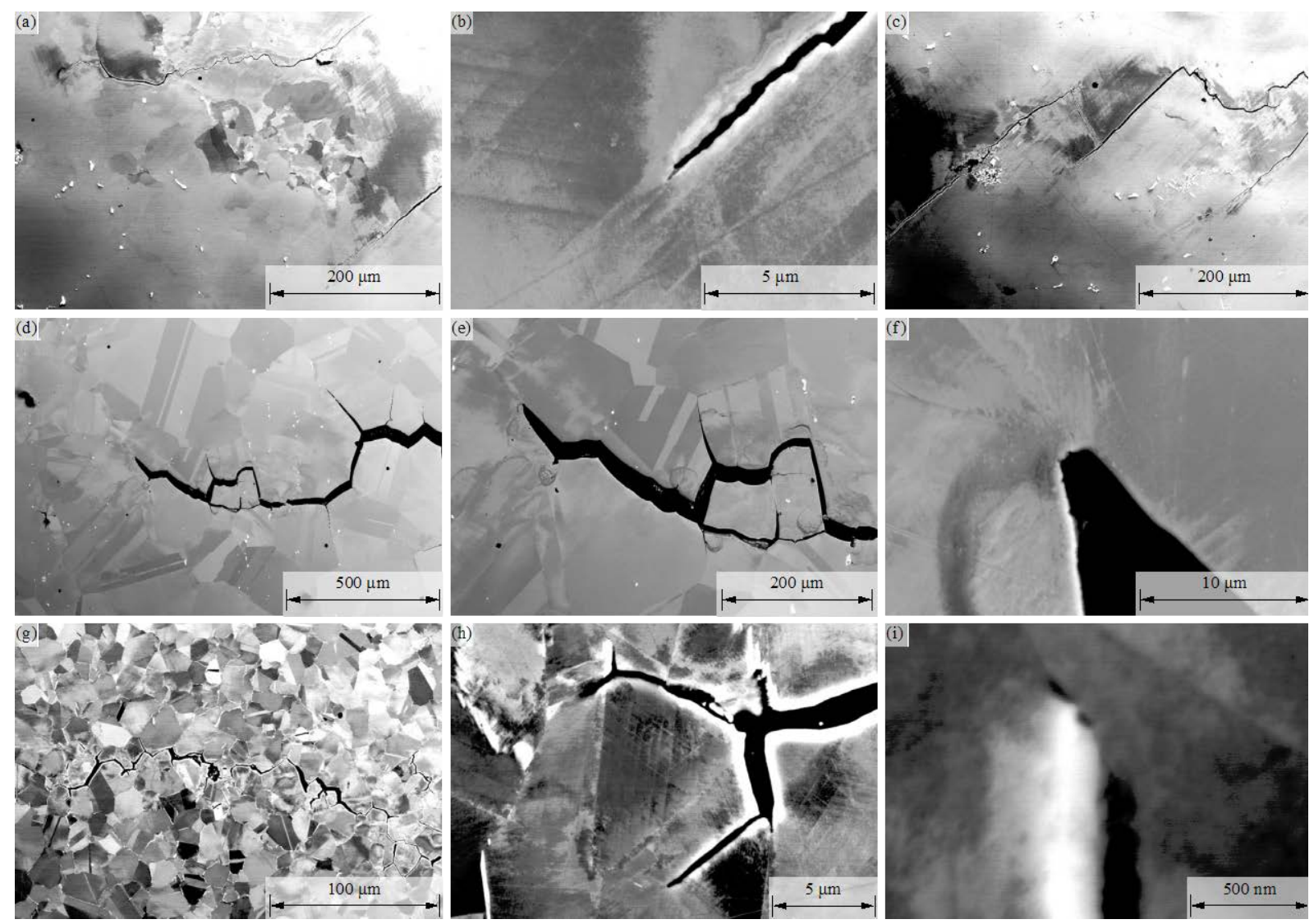

Figure 2. General microstructure, crack propagation, and crack tip blunting in (a)-(c) cast, (d)-(f) grain enlarged bar, and (g)-(i) fine grained bar material.

EBSD analysis, Fig. 3, adds further information regarding grain orientation and grain size for (a) cast (b) grain enlarged bar, and (c) fine grained bar with grain sizes $>700 \mu \mathrm{m}, 200$ $\mu \mathrm{m}$, and $20 \mu \mathrm{m}$ respectively.

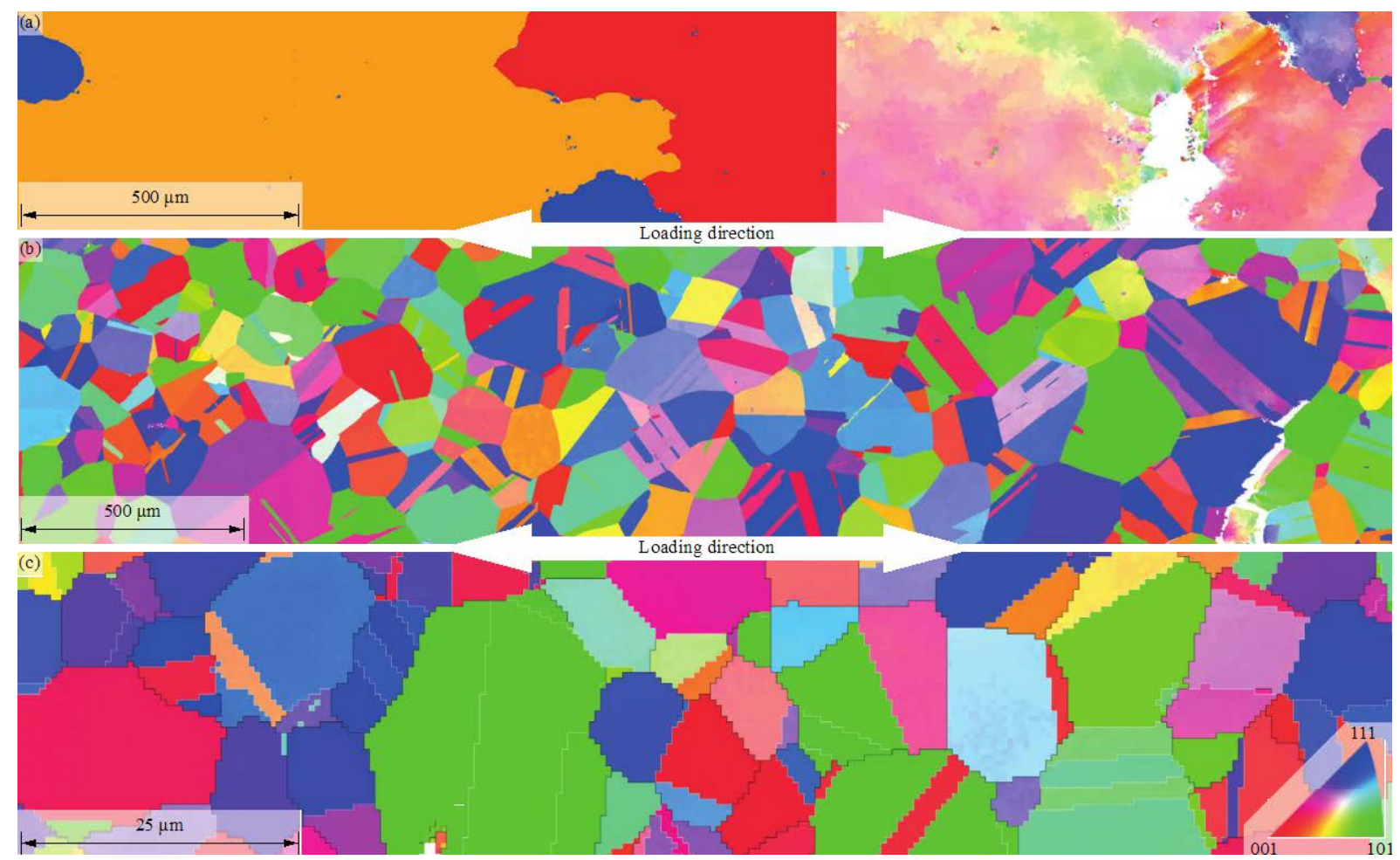

Figure 3. OIM:s of the microstructure of the (a) cast, (b) grain enlarged bar, and (c) fine- 
grained bar material respectively.

All "pure fatigue" samples exhibit the same striation formation behaviour, seen in Fig. 4 (a)-(c), with the main difference being the striation spacing. The cast sample has the smallest striation spacing followed by the grain enlarged bar and finally the fine-grained bar. Striations "bend" when encountering discontinuities such as hard inclusions and grain boundaries, depicted in Fig. 4 (b) and (c). Samples subjected to dwell-fatigue and creep displays the same fracture features, i.e., intergranular crack propagation and flat surfaces as displayed in Fig. 4 (d)-(f).
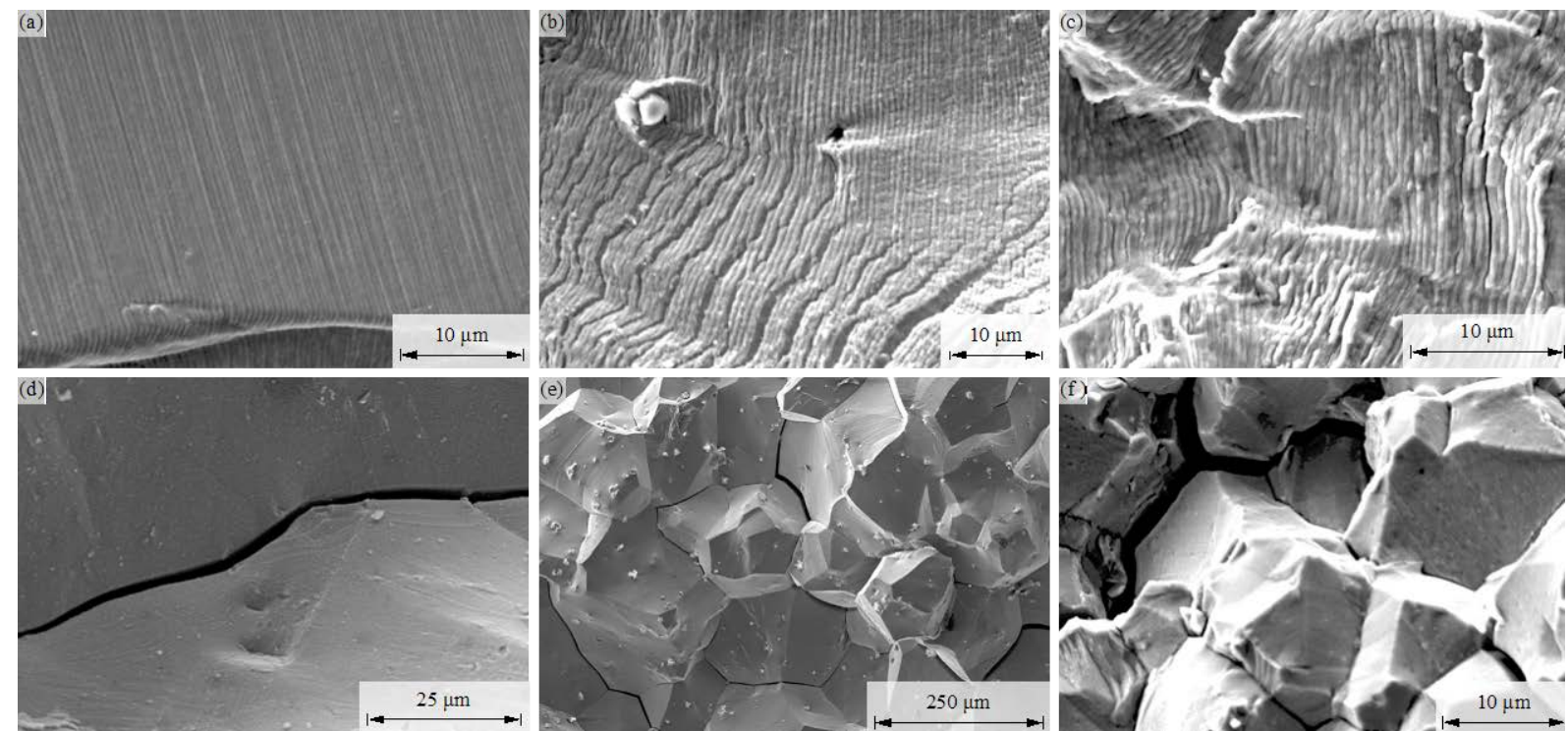

Figure 4. General fracture surfaces of the "pure fatigue" (a) cast, (b) grain enlarged bar, and (c) fine grained bar material respectively and the creep affected fracture surfaces of the (d) cast, (e) grain enlarged bar, and (f) fine grained bar material respectively.

\section{Discussion}

Nickel-base superalloys such as Inconel 718 find considerable application in gas turbine engine components, i.e., wrought fine grained polycrystalline gas turbine discs which operate in the intermediate temperature range of $450{ }^{\circ} \mathrm{C}$ to $650{ }^{\circ} \mathrm{C}$. Inconel 718 is in many situations limited by its susceptibility to fast intergranular cracking during extended dwell-times at high temperatures and high tensile stresses. ${ }^{[29]}$ Time dependent intergranular cracking of nickelbase superalloys, under both sustained and cyclic loads, is dominated by environmental interactions with oxygen and/or other embrittling species at the crack tip resulting in dynamic embrittlement (DE) or stress accelerated grain boundary oxidation (SAGBO). ${ }^{[30][31]}$ Complex oxides of $\mathrm{Ni}, \mathrm{Cr}$, and $\mathrm{Fe}$, as well as oxides formed from niobium carbides along grain boundaries, can be formed at the crack tip in Inconel 718. ${ }^{[32][33]}$ Crack propagation rate acceleration in combination with dwell-times is typically associated with a transition from transgranular to intergranular crack propagation behaviour. Retardation of crack propagation rates is analogous with a significant degree of plastic deformation, crack tip blunting and branching. Creep deformation will lead to stress relaxation ahead of the crack tip that will reduce the crack propagation rate. ${ }^{[6]-[8]}$

Fig. 1 illustrates the cycle and time dependent crack propagation rate results in which the fine-grained creep samples exhibited similar crack propagation rates. It also shows that the deviation in samples from the same batch is quite small, making it possible to use less samples for crack propagation characteristics for Inconel 718. The grain enlarged bar exhibited slower time dependent crack propagation than the fine-grained bar. This could be 
due to the difference in yield strength at $550{ }^{\circ} \mathrm{C}$, where the fine-grained bar exhibited the highest yield strength of $\sim 1100 \mathrm{MPa}$, followed by grain enlarged bar $\sim 900 \mathrm{MPa}$ and lastly the cast which should theoretically be in the range of 700-800 MPa. Depending on the yield strength the size of the plastic zone would change from a relatively small one in the finegrained bar, Fig. 2 (g), and become larger with an increasing grain size as seen in (a) and (d). The plastic zone is well known to retard crack propagation which can also lead to blunting, illustrated in Fig. 2 (b), (e), (f), (h), and (i), and in some cases fully hinder crack propagation as was seen in the cast dwell-time sample. It could also be due to the larger grains, resulting in a "higher amplitude" and "longer wave length" for the crack to propagate through, giving the same projected crack length, vis-á-vis the fine-grained bar, Fig. 2 (g), samples exhibited more orthogonal crack propagation compared to the loading direction giving a "lower amplitude" and a "shorter wave length". The difference in cyclic crack propagation rates between the "pure fatigue" and dwell-time samples were approximately a factor ten for the fine grained and grain enlarged bar. Cast samples on the other hand showed no or minute differences between the "pure fatigue" and dwell-fatigue samples. Our cyclic and dwell-fatigue crack propagation rates for the fine-grained bar are well in line with that reported in ${ }^{[10]}$ but slower than that reported by Gustafsson et al. ${ }^{[34]}$. The grain enlarged bar shows similar crack propagation as that reported of $90 \mathrm{~s}$ CT dwell-fatigue samples. ${ }^{[17]}$ Both "pure fatigue" and dwell-fatigue cast samples exhibit similar crack propagation rates as seen for the "pure fatigue" samples. ${ }^{[10]}$ During "pure fatigue" testing the cast sample exhibited transgranular crack propagation compared to intergranular and/or crystallographic crack propagation illustrated in Fig. 2 (c) when dwell-times were introduced. The effect of crystallographic crack propagation is most likely due to the lack of grain boundaries which forces the crack to propagate through preferred $\{111\}$ crystal planes. The angle between two adjacent 111-planes is $70.5^{\circ}$ which can be seen in Fig. 2 (b) and (h). As a result of dwell-fatigue, crystallographic slip can result in a crack appearance similar to that of a creep test and also enable branching as seen in Fig. 2 (a). The local plastic deformation ahead of the crack tip, retards the crack propagation and redirects the crack in one or more directions giving rise to the observed local recrystallization between branches and the main crack in Fig. 2 (a). This shows that extensive testing is needed in order to obtain accurate crack propagating parameters for life modeling purposes.

Small amounts of $\delta$-phases were observed in the cast and grain enlarged bar material, since both materials were heat treated above the $\delta$-solvus temperature. However, the observed crack path does not seem to follow the $\delta$-phases which has been reported for Inconel 718 containing a higher amount of $\delta$-phase. ${ }^{[15][17]}$ In the fine-grained bar, $\delta$-phases with no preferred orientation were observed, mainly located in grain boundaries, Fig. 2 (g)-(i). Therefore, no clear or apparent effect of how $\delta$-phases or forming induced $\delta$-phases might affect crack propagation can be drawn from these tests compared to tests done on real components such as turbine discs in ${ }^{[15][17]}$ in which it has been shown that the orientation of $\delta$-phases does affect crack propagation immensely. In the fine-grained bar subjected to dwelltimes and creep, crack propagation mainly took place as intergranularly in the $\gamma / \delta$ interphase as illustrated in Fig. 2 (i), which has also been reported. ${ }^{[15][17]}$

Crack tip blunting was observed in all dwell-time and creep samples as seen in Fig. 2 (b), (g), (f), (h), and (i). The main difference was that microvoids in front of the crack tip were observed in the fine-grained bar, Fig. 2 (i), and cast material, Fig. 2 (b), which have also been observed in Inconel $718 \mathrm{~Kb}$ test samples subjected to overloads. ${ }^{[10]}$ The lack of microvoids in the grain enlarged bar samples, Fig 2 (d)-(f), could be due to the more severe amount of crack tip blunting present.

EBSD was used to estimate grain sizes for the three different materials. Even though quite large maps were produced using an appropriate step size, not enough grains could be mapped in order to accurately estimate the "real” grain size, especially for the cast material. 
Instead, ocular inspection was implemented, resulting in the approximate grain sizes: fine grained bar $\sim 20 \mu \mathrm{m}$, grain enlarged bar $\sim 200 \mu \mathrm{m}$, and cast $>700 \mu \mathrm{m}$. Amount of CSL grain boundaries was similar to those reported in ${ }^{[17]}$ and can therefore not be used to solely explain the difference in crack propagation rates.

All "pure fatigue" samples exhibit the same striation formation behaviour seen Fig. 4 (a)-(c) with the main difference being the striation spacing. What could be crystallographic slip or arrested crack branching is illustrated in the cross-sectional image shown in Fig. 5 (b) for the grain enlarged bar. This could be the explanation for the cleavage like behavior seen on the fracture surface in Fig. 4 (b). All dwell- fatigue and creep samples exhibit similar fracture features, i.e., intergranular crack propagation and flat surfaces displayed in Fig. 4 (d)(f) which is in line with the findings in. ${ }^{[10]}$

Fig. 5 illustrates an oxidised grain boundary through which a crack is propagating. This effect of crack propagation through an oxide is generally explained as SAGBO. SAGBO is the most likely reason behind the observed dwell-time effect seen in Fig. 1 (a), which have also been observed and reported. ${ }^{[10][17][35]}$ The cast material did not exhibit any significant dwell-time effect. The anomaly in the cast dwell-fatigue curve is due to the fact that the cast dwell-fatigue sample stalled most likely due to plastic deformation in front of the crack tip. After which it was cycled further in order for the crack to propagate further.
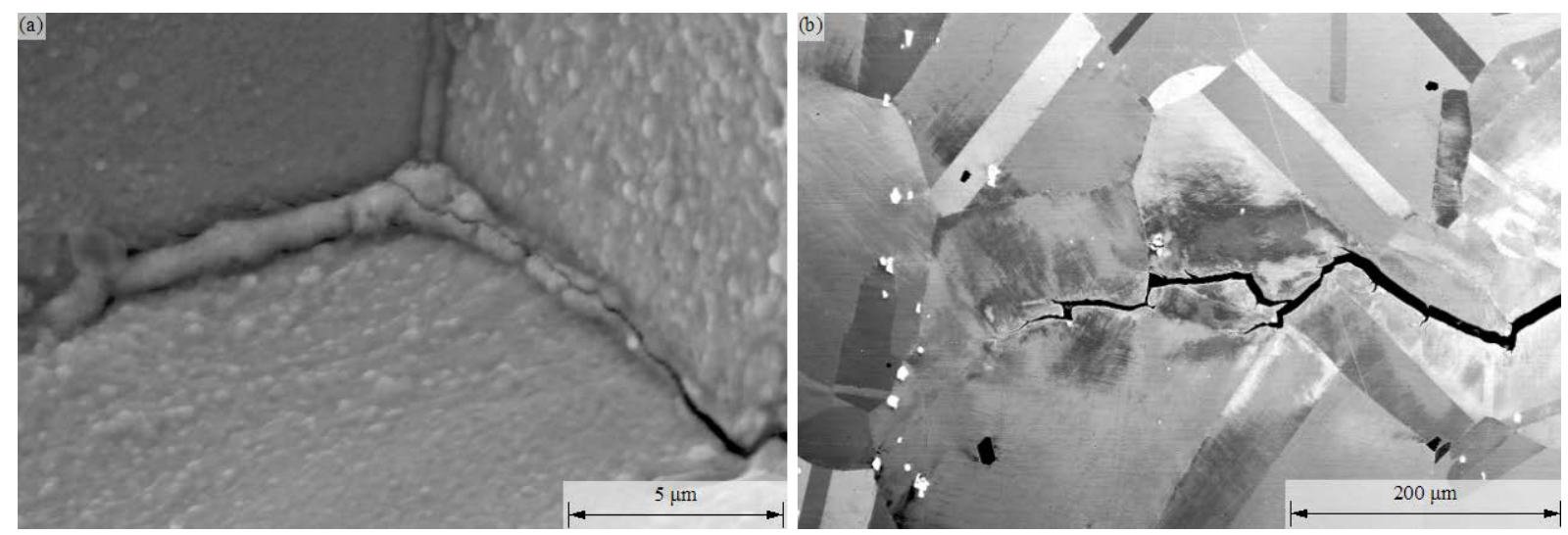

Figure 5. A crack propagating through an oxidized grain boundary in the cast dwell-time sample, a mechanism generally referred to as SAGBO in literature is seen in (a). In (b) arrested branching can be seen in the grain enlarged bar subjected to "pure fatigue".

\section{Conclusions}

Fatigue crack propagation tests were performed using Inconel $718 \mathrm{~Kb}$ test samples. To investigate how grain size affects crack propagation behaviour during "pure fatigue", dwellfatigue, and creep, a test series was run at $550{ }^{\circ} \mathrm{C}$. The following conclusions can be drawn from this work:

- "Pure fatigue" and cast dwell-fatigue samples exhibited similar cyclic crack propagation rates. No apparent dwell-time effects could be seen when comparing the cast samples.

- During "pure fatigue" of the fine-grained bar, the crack propagation was approximately a factor five faster than the grain enlarged bar.

- Fine grained and grain enlarged bar dwell-fatigue samples showed a cyclic crack propagation rate approximately a factor ten faster than the "pure fatigue" samples.

- Time dependent crack propagation rates are strongly affected by grain size. Propagation rates increase with decreasing grain size.

- The fine grained and grain enlarged bar samples subjected to dwell-fatigue and creep exhibited intergranular crack propagation and crack tip blunting. Compared to the cast 
dwell-fatigue sample where crystallographic crack propagation in 111-planes as well as crack tip blunting could be seen.

\section{Acknowledgements}

The authors would like to thank Agora Materiae, graduate school, Faculty grant SFO-MATLiU\#2009-00971, and the project teams at Linköping University, Siemens Industrial Turbomachinery $A B$ and GKN Aerospace Engine Systems for valuable discussions. This research has been funded by the Swedish Energy Agency, Siemens Industrial Turbomachinery $A B$, GKN Aerospace Engine Systems, and the Royal Institute of Technology through the Swedish research program TURBO POWER, the support of which is gratefully acknowledged. Also, a special thank you to Ph.D. Christopher Tholander, computer wiz and good friend.

\section{Conflict of interest}

The authors declare no conflict of interest.

\section{References}

[1] D.G. Leo Prakash, M.J. Walsh, D. Maclachlan, A.M. Korsunsky, Int. J. Fatigue 2009, 31, 1966.

[2] E. Andrieu, R. Molins, H. Ghonem, A. Pineau, Mater. Sci. Eng. A 1992, 154, 21.

[3] R. Molins, G. Hochstetter, J.C. Chassaigne, E. Andrieu, Acta Mater. 1997, 45, 663.

[4] J.A. Pfaendtner, C.J. Mcmahon JR., C.J. McMahon, Acta Mater. 2001, 49, 3369.

[5] J.P. Pédron, A. Pineau, Mater. Sci. Eng. 1982, 56, 143.

[6] J. Li, H.M. Wang, H.B. Tang, Mater. Sci. Eng. A 2012, 550, 97.

[7] J. Byrne, R. Hall, L. Grabowski, Int. J. Fatigue 1997, 19, 359.

[8] X. Liu, B. Kang, K. Chang, Mater. Sci. Eng. A 2003, 340, 8.

[9] D. Gustafsson, E. Lundström, Int. J. Fatigue 2013, 48, 178.

[10] J. Saarimäki, J. Moverare, R. Eriksson, S. Johansson, Mater. Sci. Eng. A 2014, 612, 398.

[11] A.K. Koul, P. Au, N. Bellinger, R. Thamburaj, W. Wallace, J.P. Immarigeon, Development of a Damage Tolerant Microstructure for Inconel 718 Turbine Disc Material, 1988.

[12] U. Krupp, J. Mater. Sci. 2008, 43, 3908.

[13] M. Gao, D.J. Dwyer, R.P. Wei, Scr. Metall. Mater. 1995, 32, 1169.

[14] J.J. Schirra, R.H. Caless, R.W. Hatala, in Superalloys 718, 625 Var. Deriv., 1991, 375.

[15] S. Ponnelle, B. Brèthes, A. Pineau, Superalloys 718, 625, 706 Deriv. 2001, 92, 307.

[16] K.S. Chan, M.P. Enright, J. Moody, S.H.K. Fitch, Metall. Mater. Trans. A Phys. Metall. Mater. Sci. 2014, 45, 287.

[17] J. Saarimäki, M.H. Colliander, J.J. Moverare, Mater. Sci. Eng. A 2017, 692, 174.

[18] F. V Antunes, J.M. Ferreira, C.M. Branco, J. Byrne, Fatigue Fract. Eng. Mater. Struct. 2001, 24, 127.

[19] M.R. Bache, W.J. Evans, M.C. Hardy, Int. J. Fatigue 1999, 21, 69.

[20] C.M. Branco, J. Baptista, J. Byrne, Mater. High Temp. 1999, 16, 27. 
[21] P. Heuler, E. Affeldt, R.J.H. Wanhill, Materwiss. Werksttech. 2003, 34, 790.

[22] E. Storgärds, K. Simonsson, S. Sjöström, Theor. Appl. Fract. Mech. 2016, 81, 2.

[23] D.D. Krueger, R.H. Antolovich, R.H. Van Stone, Metall. Trans. A 1987, 18A, 1431.

[24] E. Storgärds, J. Saarimäki, K. Simonsson, S. Sjöström, D. Gustafsson, T. Månsson, J. Moverare, J. Eng. Gas Turbines Power 2015, 138, 1.

[25] J. Saarimäki, 2017.

[26] J. Saarimäki, 2017.

[27] J. Saarimäki, 2017.

[28] R.J. Kamaladasa, Y.N. Picard, Microsc. Sci. Technol. Appl. Eduaction 2010, 3, 1583.

[29] J. Moverare, D. Gustafsson, Mater. Sci. Eng. A 2011, 528, 8660.

[30] K. Wackermann, U. Krupp, H.J. Christ, in ASTM Spec. Tech. Publ., 2011, 297.

[31] D.A. Woodford, Energy Mater. Mater. Sci. Eng. Energy Syst. 2006, 1, 59.

[32] M. Gao, D.J. Dwyer, R.P. Wei, in Superalloys 718, 625, 706 Var. Deriv., 1994, 581.

[33] L. Viskari, M. Hörnqvist, K.L. Moore, Y. Cao, K. Stiller, Acta Mater. 2013, 61, 3630.

[34] D. Gustafsson, J.J. Moverare, S. Johansson, K. Simonsson, M. Hörnqvist, T. Månsson, S. Sjöström, Int. J. Fatigue 2011, 33, 1461.

[35] J. Saarimäki, J.J. Moverare, M.H. Colliander, Mater. Sci. Eng. A 2016, 658, 463. 